\title{
LA OPERACIÓN MARQUETALIA, UNA EXPRESIÓN DE LA LUCHA GLOBAL CONTRA LA INSURGENCIA COMUNISTA ${ }^{1}$
}

\author{
Carlos Felipe Cifuentes Rojas ${ }^{2}$ \\ Jimmy AleXÁNDER Holguín Alzate ${ }^{3}$
}

\section{RESUMEN}

El objetivo de este capítulo es mostrar las conexiones globales de la Operación Marquetalia, con el fin de comprender sus dinámicas propias, tanto por parte de las Fuerzas Militares como de los campesinos rebeldes. Para ello se analizará el carácter global de la lucha anticomunista, la llegada de las tácticas contrainsurgentes a Colombia y, por último, las acciones de la Operación Marquetalia. Este análisis permitirá contrastar las versiones de las partes enfrentadas, toda vez que desde el discurso, de uno y otro lado, se busca magnificar las gestas militares propias y minimizar las del oponente obviando, en muchos casos, la objetividad.

Palabras claves: contrainsurgencia, Alianza para el progreso, Marquetalia, Fuerzas Militares, tácticas cívico-militares.

\section{INTRODUCCIÓN}

La victoria de la Revolución Cubana en 1959 alteró la política de los Estados Unidos en el hemisferio. El compromiso con la lucha contra el

Este capítulo se ha desarrollado como parte del trabajo de investigación del grupo Análisis de contexto, registrado en Colciencias.

2 Doctor en historia de la Universidad de los Andes y profesor ocasional de la Pontificia Universidad Javeriana. Sus intereses de investigación incluyen la historia de las relaciones exteriores colombianas y sudamericanas en los siglos XIX y XX y su relación con aspectos globales.

3 Sargento Primero de la Reserva Activa del Ejército Nacional. Tecnólogo en administración y análisis de la seguridad. Analista militar, especialista en la historia de las FARC. 
comunismo se extendió a todos los países latinoamericanos dentro de políticas estadounidenses, tales como el Plan LASSO y la Alianza para el Progreso. Esas políticas implicaron acciones de tipo cívico militar para las cuales los Estados Unidos tuvieron un rol central, tanto en la asistencia y asesoramiento militar, como para el desarrollo económico y social de todos los países latinoamericanos (Alianza PARA el Progreso, 1961). En Colombia, dentro de ese contexto continental, algunos grupos de autodefensas campesinas fueron girando hacia la izquierda y adoptando el comunismo como ideología (PÉCAUT, 2008). Dentro de este grupo sobresale el de la república independiente de Marquetalia, a la que el Estado colombiano combatió bajo el paraguas del Plan $\mathrm{Lazo}^{4}$ y los principios de la Alianza para el Progreso, con el apoyo de los Estados Unidos.

La Operación Soberanía, comúnmente conocida como Marquetalia, fue una acción conjunta de las Fuerzas Militares colombianas con el fin de pacificar esa región en el sur del Tolima y parte del Huila, a mediados de 1964, controlada por campesinos procomunistas. Esta operación estuvo ubicada dentro de lo que Daniel Emilio Rojas (2017) llama una geografía global del combate. Sus dinámicas se logran entender dentro de un contexto más amplio, en el que la lucha contra el comunismo y la guerra irregular tienen un rol central. Así, en el desarrollo de la Operación Marquetalia se desplegaron tácticas y estrategias cívico militares desarrolladas y perfeccionadas en diferentes escenarios globales, tales como Corea, Filipinas, Argelia y Vietnam (REmPE, 1995; D. E. RoJAs, 2017).

La participación del batallón Colombia en uno de esos escenarios -la guerra de Corea (1951-1953) - fue un impulso en la modernización del Ejército colombiano, en cuanto a tácticas y equipamiento, entre otras (AtehortúA, 2008; MelÉNDEZ, 2015). Las tácticas contrainsurgentes aprendidas en Asia por soldados colombianos modificaron la manera de combate en Colombia contra las embrionarias guerrillas en las escarpadas montañas del país (DuforT, 2013; RuIz NovOA, 1956). Esa modernización alteró la finalidad de las Fuerzas Militares colombianas, pasando de ser exclusivamente las salvaguardas de las fronteras, para dedicarse a

El Plan LASO es diferente al Plan Lazo. El primero se trata de una estrategia estadounidense para combatir la expansión del comunismo en América, mientras que el último es un plan trazado por las Fuerzas Militares colombianas que establecía los lineamientos de la lucha contrainsurgente, basada en acciones cívico militares. 
preservar la seguridad interna, por medio de la lucha contra la insurgencia (RUEDA, 2000). Esa lucha contrainsurgente tuvo un importante apoyo por parte de las instituciones y las Fuerzas Militares de los Estados Unidos, que proveyeron dinero, equipamiento y entrenamiento, en el contexto del Plan LASSO y la Alianza por el Progreso, y del combatir el comunismo en todo el continente americano (REMPE, 1995; D. E. RoJAS, 2017).

La Operación Marquetalia, tal como la lucha contrainsurgente en otras partes del mundo, tuvo dos componentes. Uno de carácter cívico, en el que se adelantaron obras públicas y el Estado colombiano buscó hacer presencia en las zonas controladas por los campesinos; $y$, otro de carácter militar en el que las Fuerzas Militares, de manera conjunta, hicieron una incursión por aire a la república independiente (Comisión NaCiONAL De REPARACIÓN Y RECONCILIACIÓN, 2013; Dufort, 2013; Molano, 2017; Pizarro Leongómez, 1987; Rempe, 1995). Para las FARC-EP el desarrollo de esa operación se convirtió en su mito de fundación, por lo que en diferentes documentos y entrevistas a miembros de esa guerrilla se ha tendido a exaltar la resistencia de un puñado de campesinos contra un gran número de soldados, que utilizaron toda clase de estrategias, limpias y sucias, para tomar control de la zona de Marquetalia (ALAPE, 1989; ARENAS, 2000; SANTRICH, s.f.; VÉLEZ, s. f.). Este relato inspiró y dio fundamento a la lucha subversiva que adelantaron las FARC-EP por más de 50 años (Olave, 2013).

El objetivo de este capítulo es ubicar la Operación Marquetalia en un contexto más amplio, para comprender sus dinámicas propias, tanto por parte de las Fuerzas Militares como de los campesinos. Este artículo se dividirá en tres partes. Una primera analiza el carácter global de la lucha anticomunista en el mundo en dos vertientes - una militar, con escenarios en Filipinas, Corea y Vietnam y otra política, teniendo como eje el Plan LASSO y la Alianza para el Progreso, planes estadounidenses para afrontar la amenaza comunista en Latinoamérica-. La segunda parte abordará la manera en que las tácticas contrainsurgentes llegaron a Colombia por medio de la colaboración estadounidense y la formulación del plan Lazo, de carácter cívico militar, por el General Ruiz Novoa. Por último, en la tercera parte, se analizarán las acciones de la Operación Marquetalia, tanto las cívicas como las militares, mostrando cómo se convirtió en la primera en la que participaron conjuntamente todas las 
Fuerzas Militares colombianas, respondiendo a un contexto global que permite comprender tanto el accionar y los discursos de las Fuerzas, como de los campesinos comunistas en la región de Marquetalia.

\section{LA LUCHA GLOBAL CONTRA EL COMUNISMO Y LA MACARTIZACIÓN COLOMBIANA}

El fin de la Segunda Guerra Mundial marcó el inicio de una competencia de las potencias globales -la Unión Soviética y los Estados Unidos- para expandir sus zonas de influencia en todo el orbe. Esa competencia coincidió con un proceso de descolonización en Asia y África, donde las antiguas colonias, que reasumieron su soberanía, se inclinaron hacia una u otra potencia, dependiendo de los beneficios que podrían obtener (DUARA, 2004; RoTHERMUND, 2006). Así mismo, las acciones de Japón en la Segunda Guerra Mundial generaron resistencias contra la invasión, como lo fue el caso en Corea y Filipinas, donde luego del fin de la guerra, esos ejércitos de resistencia se inclinaron hacia el comunismo y generaron malestar en el gobierno de los Estados Unidos que buscó combatirlos (JERVIS, 1980; LAPHAM \& NorLING, 1996; STUECK, 1997; VALERIANO \& BohANNAN, 2006). La lucha contra los insurgentes en Asia y África se caracterizó por ser de carácter no convencional y asimétrico, y las fuerzas que combatieron allí tuvieron que adaptarse a esa forma de combate.

Los primeros escenarios que presenciaron el cambio de guerra fueron Filipinas y Corea. Allí, el esquema para combatir a las guerrillas combinó acciones cívicas y militares, basadas en la formación de los soldados por la CIA, así como la creación de unidades móviles con capacidad de emplear tácticas de guerra psicológica y el desarrollo de programas sociales (JERVIS, 1980; D. E. RoJAS, 2017, p. 58; VALERIANO \& BOHANNAN, 2006). A partir de esas confrontaciones se extendió el uso de tácticas cívico militares en las luchas que buscaban combatir a los insurgentes por diferentes medios, más allá del militar. Entre esas tácticas se cuenta la inteligencia y contrainteligencia y la búsqueda del retiro del apoyo de las comunidades a esos grupos por medio de la promoción del Estado, a través de obras sociales principalmente (United States Army, 1962). Ahora bien, en la lucha contra el comunismo internacional, los Estados Unidos 
contaban con aliados en todo el mundo, entre los que estaba Colombia. El gobierno de Mariano Ospina expresó su apoyo cabal a la "defensa" de la península coreana, amenazada por el comunismo (PIZARRo LEONGóMEZ, 1987). De esa manera, Colombia se iba transformando en el aliado más firme de los Estados Unidos en Latinoamérica, gracias a lo cual, algunos años más adelante, cuando la lucha contra el comunismo se instaló en ese país, los Estados Unidos colaboró de manera activa con su aliado continental por medio de políticas sociales y entrenamiento táctico a las Fuerzas Militares colombianas (AvILES, 2006).

En diciembre de 1950 se creó el batallón de Infantería No. 1 Colombia. Este cuerpo fue entrenado en los Estados Unidos en tácticas de guerra irregular, por medio de manuales con alto contenido ideológico y patriótico. En junio de 1951 iniciaron formalmente las acciones militares colombianas en Corea (ATEHORTÚA, 2008; MELÉNDEZ, 2015). Las acciones allí desarrolladas por los soldados colombianos estuvieron dentro del ámbito de las tácticas cívico militares, por lo que fueron asimiladas por los militares que formaron parte del batallón. La participación de los militares colombianos en la guerra de Corea les permitió perfeccionar tácticas de guerra, así como mejorar la comunicación por radio y entender la importancia de la inteligencia y contrainteligencia en las zonas de combate (D. E. RoJAS, 2017).

Paralelo a la participación del batallón Colombia en Corea, la alianza entre los gobiernos colombiano y estadounidense adquiría un nuevo matiz. En 1952, estos gobiernos firmaron el Pacto de Asistencia MilitarPAM. Uno de los puntos centrales del PAM fue la modernización de equipos militares de las Fuerzas Militares. Gracias a ello, el Gobierno colombiano recibió ayuda militar, compuesta por un lote de rifles M-1 calibre 30, camiones de dos y medio toneladas, cazabombarderos y municiones de diverso calibre (Pizarro Leongómez, 1987; PrÉSIGA Romero, 2018; RAMSEY, 1981; Rojas Delgado ET AL., 2017). Asimismo, entre 1953 y 1954 llegaron a Colombia helicópteros H-23 Raven y H-13 Sioux, dos modelos de helicópteros de reconocimiento y evacuación que se habían empleado intensivamente en Corea (ORTEGA, 2006). La llegada de ese material bélico impulsó la creación de la primera base de helicópteros en Colombia (CAATA-1: Comando Aéreo de Apoyo Aerotáctico), y la Escuela de Lanceros, enfocada en el entrenamiento en guerra no convencional (D. E. RoJAs, 2017). 
Esos primeros pasos en la modernización de las Fuerzas Militares colombianas recibieron un nuevo impulso con la vuelta del batallón Colombia al país. Los soldados que volvieron, además de obtener una vasta experiencia militar, llegaron con una nueva forma de entender el papel de las Fuerzas Militares en Colombia. Así, 'los coreanos', como fueron conocidos, entendían que para combatir los brotes de comunismo no solo bastaba con las acciones de confrontación armada; estas deberían estar acompañadas de acciones políticas, económicas y sociales (NIETO, 2014, Ruiz NovoA, 1956). El ascenso de Alberto Ruiz Novoa, Álvaro Valencia Tovar, Fernando Landazábal Reyes y otros oficiales que participaron en Corea fue determinante para que las Fuerzas Militares cambiaran paulatinamente su finalidad, pasando de ser exclusivamente las salvaguardas de las fronteras, para dedicarse a preservar la seguridad interna, amenazada por grupos de bandoleros y guerrilleros en diferentes puntos del país (DUFORT, 2013; RUEDA, 2000). El punto de inflexión en la ofensiva contra el comunismo por parte del gobierno estadounidense fue el triunfo de la Revolución Cubana, iniciando 1959. A partir de ese momento, la prioridad de los Estados Unidos fue evitar que el comunismo tuviera otra victoria en el continente (DAMMS, 2019; STODDEN \& WeISS, 2017; United States Congress, 1960; Whitaker, 1960). Para el caso colombiano, el gobierno de Eisenhower autorizó al Departamento de Estado el envío a Colombia de un equipo de expertos que evaluara las condiciones de seguridad interna del país e hiciera recomendaciones con el fin de evitar el avance del comunismo (REMPE, 1995).

Así, en octubre de 1959 arribó a Colombia el US Special Survey Team. El equipo estaba conformado por expertos militares con amplia experiencia contrainsurgente en Filipinas, Corea y Vietnam. El informe del SurveyTeam advirtió que el bandolerismo campesino se podría convertir en focos guerrilleros comunistas, animados por el ejemplo cubano. Para contenerlo, el grupo hizo énfasis en que el gobierno de Alberto Lleras Camargo (1958-1962), el primero del Frente Nacional, debía enfocarse en la lucha contra el bandolerismo. Para combatirlos, el gobierno necesitaba restaurar la confianza en el Estado y las Fuerzas Militares, en aquellas regiones controladas por campesinos insurgentes, tal como recomendaba Ruiz Novoa. Asimismo, el informe sugería combatir a los bandoleros militarmente con unidades móviles de lanceros. 
Sin embargo, la estrategia militar debería modificarse a mediano plazo y el Gobierno colombiano debería fortalecer el servicio de inteligencia y la implementación de programas de guerra psicológica, información pública y acción cívica (Pizarro, 1991; RemPe, 1995; Rojas Delgado ET AL., 2017). Este informe fue el inicio de la cooperación de Estados Unidos con Colombia en la lucha contrainsurgente dentro de la geografía global del combate.

La posición de Colombia en esa geografía no fue marginal, de hecho el interés de los Estados Unidos era poner a Colombia en la vanguardia de la lucha contra el comunismo en el contexto del PAM y del Programa de Seguridad Interna en el Extranjero. El Departamento de Defensa estadounidense, entonces, analizó el informe del equipo y entendió que las Fuerzas Militares colombianas requerían de una mayor capacitación en tácticas contrainsurgentes y de una mejoría en su equipo militar. Por ello, finalizando 1961, las Fuerzas Militares colombianas recibieron un "envío de impacto especial" de aproximadamente 1.5 millones de dólares en equipo militar. El "envío" contenía tres helicópteros H-43B (medianos), así como una variedad de vehículos, algunos equipos de comunicación y armas pequeñas que servirían para equipar y movilizar unidades especializadas de tipo Lancero contra los campesinos insurgentes (REMPE, 1995). Con el cambio de gobierno en los Estados Unidos, en 1962, un nuevo equipo visitó Colombia para observar y analizar la situación de seguridad interna del país. El equipo estuvo dirigido por el Brigadier General William P. Yarborough y emitió un concepto del estado de la lucha contrainsurgente en Colombia. El informe del equipo Yarborough fue diferente del SurveyTeam, en tanto que no hacía tanto énfasis en las acciones sociales, cívicas y políticas como medio para alcanzar la victoria, sino que se concentró en la evaluación del estado de las Fuerzas Militares y su posición en la guerra contrainsurgente en el país. El informe concluyó que la fragmentación de los recursos y la acción de las Fuerzas Militares, la dificultad de comunicaciones efectivas e inmediatas, las fallas en el transporte y equipo, así como la dependencia de puestos avanzados estáticos pusieron al Ejército a la defensiva y permitieron que los elementos subversivos adquirieran la iniciativa (REMPE, 1995). Como recomendación, el informe del equipo Yarborough concluyó proponiendo que los Estados Unidos proveyeran 
la guía y asistencia en todos los aspectos de la lucha contrainsurgente, no solo los militares, sino también los cívicos y los sociales, a los que les faltaba un impulso para que el apoyo de las comunidades se retirara de los bandoleros y se movilizara hacia el Estado colombiano.

Los reportes de estos equipos, en general, recomendaban a los Estados Unidos una participación más activa en la lucha contrainsurgente en Colombia. Los tres puntos en los que ese país debía concentrar su ayuda eran en el adiestramiento militar, en la modernización de equipos y en el apoyo al Estado colombiano para el desarrollo de políticas sociales. Esos tres mismos puntos estaban consignados en la Alianza para el Progreso, impulsada por el gobierno Kennedy, como contrapeso al avance del comunismo en el continente (Alianza PARA EL Progreso, 1961). La Alianza para el Progreso fue una iniciativa estadounidense en el seno de la Organización de Estados Americanos (OEA), materializada en 1961, para generar condiciones para el desarrollo y la estabilidad política en el continente. La idea de esta iniciativa surgió, entre otras, de la iniciativa del gobierno estadounidense, de su idoneidad para promover el progreso en América, al ser ellos quienes reconstruyeron, en gran medida, a Europa tras la Segunda Guerra Mundial (D. M. RoJAs, 2010). La Alianza para el Progreso, entonces, buscaba extender la noción de desarrollo del gobierno estadounidense en el continente, a través de cooperación financiera y técnica, para contribuir en el fortalecimiento de las instituciones democráticas, principalmente. Las asistencias eran en dos frentes. Por un lado, los Estados Unidos darían ayudas económicas para programas sociales y la construcción de caminos, que ascenderían a un billón de dólares, a través de la Agencia de los Estados Unidos para el Desarrollo Internacional-U.S. AID. Por otro lado, el Ejército estadounidense otorgaría asistencia y asesoramiento militar con el fin de combatir cualquier elemento subversivo por medio de tácticas de guerra irregular (Alianza PARA El Progreso, 1961).

En Colombia, la Alianza para el Progreso motivó la formulación del Plan Lazo por el ministro de Guerra, General Ruiz Novoa, quien hacía parte de un grupo reformista de las Fuerzas Militares. Ruiz Novoa era un 'coreano' que había absorbido las tácticas cívico militares y la guerra psicológica. Con el cambio de gobierno, Guillermo León Valencia lo 
mantuvo a la cabeza del Ministerio de Guerra, desde donde formuló el Plan Lazo. El Plan tenía como objetivo hacer frente a la insurgencia en el país, al retirar el apoyo de las comunidades a esos grupos insurgentes por medio de operaciones cívico militares y la ejecución de operaciones psicológicas, destinadas a la comprensión recíproca y al entendimiento de las necesidades de las comunidades y sus aspiraciones. El Plan Lazo fue diseñado para ejecutarse a partir del 1 de junio de 1962 hasta el 30 de marzo de 1963, mediante acciones civiles y operaciones militares (Santos Pico, Mejía Roa, \& Mesa Moncada, 2007; Valencia Tovar, 1993). Tanto el componente militar como el cívico del Plan Lazo tuvieron diferentes directrices. En cuanto al primero, cabe mencionarse que las indicaciones iban en pro de modernizar las Fuerzas Militares colombianas, por medio de entrenamiento táctico, el uso de inteligencia y contrainteligencia y la acción conjunta de ellas. Los puntos más importantes del componente militar fueron:

1. Extensión del servicio militar obligatorio con el fin de aprovechar por un mayor lapso el rendimiento de los soldados instruidos y veteranos

2. Creación de los centros de instrucción para que los batallones siempre estén con el máximo de su eficiencia de combate

3. Generalización de la instrucción de guerra de guerrillas a todas las armas del Ejército

4. Intensificación de los sistemas de búsqueda de información

5. Obligatoriedad de los cursos de lanceros para todos los oficiales y suboficiales del Ejército

6. Intensificación de la instrucción de tiro con armas cortas y desarrollo de la capacidad de reducción en el menor tiempo posible

7. Mejoramiento del enlace entre las unidades del Ejército y las de la FAC para asegurar un mayor apoyo de combate

8. Coordinación entre las autoridades civiles, militares, de Policía y DAS en la lucha contra los bandoleros

9. Suspensión de los puestos fijos para evitar ser objetivo de los bandoleros (El Plan Lazo, 1964). 
Ahora bien, en cuanto al componente civil del Plan Lazo, este tenía un enfoque desarrollista, así como el formulado en la Alianza para el Progreso, diseñado para erradicar el comunismo a través de programas sociales (LEAL, 1994). Este componente del Plan buscaba promover la confianza de las comunidades en el Estado colombiano y que paulatinamente retiraran su apoyo a los insurgentes. Para ello, las áreas donde se haría una mayor inversión serían la construcción de caminos y su mantenimiento, educación, centros y brigadas de salud y, por último, el establecimiento de comunicaciones eficientes entre las zonas controladas por los insurgentes y la capital colombiana. Esas acciones se desarrollaron gracias al dinero estadounidense, a través de U.S. AID (Doney, 1966; Edison, 1985).

Para la formulación del Plan Lazo, en sus componentes militar y cívico, el General Ruiz Novoa tuvo en cuenta los aprendizajes de la lucha contrainsurgente tras la guerra de Corea, pero también introdujo las recomendaciones del SurveyTeam y del equipo Yarborough, así como los principios de la Alianza para el Progreso. De esta manera, la contrainsurgencia se construyó a partir del conocimiento de personas de diferentes partes del mundo y de su interacción y, en ese sentido, el Plan Lazo se instaló dentro de ese flujo de ideas global. El Plan fue la concreción de la lucha contra el comunismo mundial en Colombia.

\section{El Plan Lazo y la eSTRATEgia CIVIL DE LA LUCHA CONTRAINSURGENTE}

La primera fase de la lucha contrainsurgente en Colombia tuvo un fuerte carácter cívico y no apeló de manera significativa a las acciones militares. Al iniciar la década de 1960, se encontraban bajo el control de bandoleros y subversivos adeptos al comunismo regiones como Marquetalia, El Pato, Río Chiquito, Guayabero, Sumapaz y la región del Río Ariari, entre otras. El Plan Lazo, formulado por Ruiz Novoa, guió las acciones del gobierno de León Valencia para enfrentar esa insurgencia comunista en el campo colombiano (LeAL, 2002). El Plan Lazo buscaba combinar las tácticas de contrainsurgencia con el componente psicológico de la "guerra irregular", para generar confianza en la población civil y lograr el apoyo popular a través de la construcción de obras públicas, jornadas de salud y alfabetización en zonas con presencia insurgente 
comunista (Rojas Delgado ET AL., 2017; ToRres, 2000). Para afrontar la violencia, Ruiz Novoa aconsejó “atacar las causas sociales y económicas, así como las razones históricas políticas para su existencia" (RuIz NovoA, 1965). Este Plan fue la única política militar de Estado formulada por las propias Fuerzas Militares, en la segunda mitad del siglo XX.

En definitiva, el objetivo principal del Plan Lazo, en palabras de Ruiz Novoa, era:

Una filosofía en el empleo de las Fuerzas Militares que nos lleve a ayudar en el subdesarrollo, o salir del subdesarrollo, por medio de la aplicación de la maquinaria militar a las necesidades del país (...) ayudando a luchar en favor de las necesidades de la población tal como equipos de transporte fluvial, terrestre y aéreo, hospitales, médicos, odontólogos, batallones de ingenieros etc. (LA REALIDAD de 1963, 1963).

El Plan Lazo pudo ser formulado y ejecutado, en buena medida, por la despolitización de las Fuerzas Militares, tras el fin de la dictadura de Gustavo Rojas Pinilla y el inicio del Frente Nacional. El proceso de despolitización bipartidista, estimulado por el reparto paritario de la burocracia estatal entre liberales y conservadores, permitió a los militares adquirir cierta autonomía, que se reflejó en su manejo del orden público y en la conservación y adquisición de prerrogativas institucionales. Con esa despolitización, las Fuerzas adquirieron una autonomía relativa al separar los espacios de los políticos y de los militares; los militares no decidirían como gobernar al país, ni los políticos interferirían en el accionar castrense (COMISIÓN NACIONAL DE REPARACIÓN Y RECONCILIACIÓN, 2013; LeAL, 2002; Moreno MANCERA, 2014).

Para realizar esas políticas sociales y las acciones cívicas del Plan Lazo, el gobierno de Guillermo León Valencia (1962-1966), segundo del Frente Nacional, conformó el Comité Nacional de Acción Cívica Militar mediante Decreto ${ }^{\circ} 1381$ del 24 de junio de 1963, en el que reunió los Ministerios de Gobierno, Guerra, Agricultura, Salud Pública, Educación Nacional y de Obras Públicas (REPública DE Colombia, 1963). Así mismo, esas políticas, como ya se dijo, contaron con un el apoyo del gobierno estadounidense por medio de ayudas económicas, principalmente, a través de U.S. AID y por medio del PAM (LEAL, 2002; Présiga Romero, 2018). Particularmente en la zona de Marquetalia, 
el impacto del programa de acción cívica comprendió cuatro áreas: la construcción de caminos y su mantenimiento, la educación, la salud pública y las comunicaciones. Además, hubo otros proyectos de acción cívica en los que las Fuerzas Militares se involucraron, tales como campamentos juveniles, proyectos de electrificación rural, mejoras en el suministro de agua potable, entre otros (DONEY, 1966; EDISON, 1985).

La construcción de caminos fue la preocupación que recibió mayor atención, en buena medida porque el gobierno estadounidense desembolsó 624.000 dólares para la construcción de la avenida del Tolima. Esta obra, iniciada en junio de 1963, proyectó la construcción de una autopista para conectar los departamentos del Tolima y el Valle del Cauca. Finalizando 1964, cerca del $75 \%$ de la autopista estuvo construida por militares, bajo la coordinación de ingenieros estadounidenses; el resto de la obra pasó a ser responsabilidad del Ministerio de Obras Públicas (Doney, 1966; EDISON, 1985).

La segunda área de impacto de la acción cívica sobre la que actuó el Gobierno colombiano fue la educación. Las Fuerzas Militares ayudaron en la construcción de escuelas rurales, proyecto con el que ya estaban comprometidas desde 1960. En un principio la construcción de esas escuelas contó con el apoyo económico del Instituto Colombiano para la Reforma Agraria-INCORA y de la Federación Colombiana de Cafeteros-Federacafé (BARBER, 1966; EdISON, 1985). La mano de obra para levantar los edificios era esencialmente de militares y, en menor medida, de civiles. Las escuelas eran construidas si se cumplían dos condiciones: que las comunidades estuviesen de acuerdo con esa construcción y el compromiso por escrito del Ministerio de Educación Nacional de mantener en funcionamiento la escuela. Además, otro esfuerzo importante de las Fuerzas Militares estuvo encaminado a combatir los altos índices de analfabetismo en sus filas, inspirado en los centros de alfabetización del ejército en Guatemala (HANNING, 1966; Smith, Kauffman \& Windle, 1969).

En cuanto a la salud pública, el Gobierno colombiano también adelantó acciones no solo en Marquetalia, sino también en el resto del país. Desde inicios de 1964 estableció centros médicos de medicina preventiva, donde se podían practicar cirugías menores y tratamiento dental para las personas que vivían en áreas remotas o afectadas por la violencia. 
Adicionalmente, la Fuerza Aérea Colombiana estableció una clínica ambulatoria a bordo de un avión PBY, para alcanzar aquellas zonas de difícil acceso por tierra. Tanto la aeronave como los suministros médicos y odontológicos fueron proveídos por el gobierno estadounidense, a través del PAM (EDISON, 1985; HANNING, 1966). La Armada colombiana también estableció clínicas ambulantes flotantes, sobre todo en los ríos Magdalena y Putumayo (BARBER, 1966). En general, esos centros de salud ambulatorios prestaron los mismos servicios que aquellos centros establecidos en tierra, pero en brigadas en momentos específicos.

Un cuarto aspecto central en las acciones cívicas y sociales del Gobierno y el Ejército colombianos fueron las comunicaciones. El interés del Gobierno pasaba por establecer comunicaciones eficientes entre Bogotá, donde funcionaban las entidades e instituciones estatales, y las regiones más distantes del país. Para ello, estableció una red de radios en el territorio nacional en enero de 1963 (DoNEY, 1966; EDISON, 1985). Las primeras estaciones de esa red de radios fueron ubicadas en San Andrés, Riohacha, Arauca, Puerto Carreño, Mitú, Leticia, Florencia y Mocoa (Smith et al., 1969). Adicional a esta iniciativa, Hernando Nieto, Teniente Coronel de la Fuerza Aérea Colombiana, planeó el establecimiento de una red de defensa civil en la que los finqueros pudieran estar en contacto entre ellos y con las Fuerzas Militares en la región. Esta iniciativa no contó con el respaldo monetario del Gobierno colombiano y no fue sino hasta 1965 que se materializó con fondos de U.S. AID y de contribuciones de algunos finqueros (EDISON, 1985).

Además de esos cuatro puntos centrales de la acción cívica en la lucha contrainsurgente, hubo otros proyectos desarrollados por el Gobierno y las Fuerzas Militares colombianas en pro de ganarse la simpatía de las comunidades donde operaban fuerzas insurgentes. Uno de esos proyectos fue la creación -decreto presidencial No. 940 de 1962- del Servicio de Aeronavegación a los Territorios Nacionales-SATENA. El objetivo de SATENA era mejorar los servicios de transporte a zonas apartadas, y con ello "aumentar los programas sanitarios y educativos, los sistemas de comunicaciones con el objeto de colaborar en las campañas asistenciales, docentes, de incremento agrícola y pecuario, de colonización, y en el fomento económico y social de tales territorios" (REPÚBLICA DE COLOMBIA, 1962). SATENA fue financiada por el Estado colombiano 
y operada enteramente por la Fuerza Aérea, que la convirtió en una aerolínea sin ánimo de lucro, que además recibió la donación de tres aviones C-47 y dos C-545 del gobierno estadounidense (EDISON, 1985).

Otros proyectos de acción cívica fueron los de electrificación rural $\mathrm{y}$ de mejoras en el suministro de agua potable. Las Fuerzas Militares colombianas fomentaron y ejecutaron ambos proyectos en zonas controladas por campesinos insurgentes. Gracias al desarrollo de esas iniciativas, a fines de 1965, se completaron 25 pozos de agua potable en aquellas áreas a las que los militares apuntaban que necesitaban asistencia (DONEY, 1966), mientras que 18 centrales eléctricas estaban en funcionamiento y que le daban prioridad a aquellas zonas golpeadas por la violencia al sur del país (SMITH ET AL., 1969).

La labor de las Fuerzas Militares fue reconocida por el presidente Guillermo León Valencia, quien en un discurso afirmó que las acciones cívico militares eran un factor decisivo en los resultados satisfactorios de la pacificación en el país. León Valencia resaltaba que el éxito de esas acciones había sido producto de la colaboración "estrecha y eficaz" entre las Fuerzas Militares y los habitantes de las regiones afectadas (EL EJÉRCITO Y EL CAMPESINO, 1963). De esta manera, se configuraba desde el Gobierno la necesidad que la violencia fuera eliminada, al utilizar todos los recursos a disposición para generar bienestar en la población civil.

En ese mismo sentido se pronunciaron el gerente del Instituto de la Reforma Agraria, Enrique Peñalosa, y la Sociedad de Agricultores de Colombia. Ambos sectores reconocían "la audaz hazaña realizada por las Fuerzas Militares en la lucha que el gobierno adelanta con tanta decisión por del restablecimiento del orden público". Así mismo resaltaban la labor de las Fuerzas Militares en el sur del país como un paso importante para el desarrollo rural y el fortalecimiento de la soberanía nacional (LAS Fuerzas Militares Se han heCho PResentes en los Programas de Reforma Agraria, 1963). Algunos campesinos, beneficiados por las acciones cívicas, reconocían su importancia en la región, sobre todo en Marquetalia (CAMPESINOS APOYAN A LAS FF.AA., 1964). Sin embargo, los sectores comunistas tildaron esas acciones como "cívico criminales", y

Es importante anotar que el gobierno colombiano adquirió los primeros C-47 en 1944 y el C-54 en 1955. 
aseguraban que por medio de ellas, el Ejército espiaba a los campesinos y podía planear la manera de realizar posibles ataques a Marquetalia (MARQUETALIA SE CONFUNDIRÁ CON COLOMBIA, SI EL APOYO A SU LUCHA SE ACRECIENTA, 1964).

El Plan Lazo, además de las acciones cívicas, también tenía presupuestado el despliegue de operaciones encubiertas y psicológicas, tal como lo recomendaban los informes del SurveyTeam (1959) y del equipo Yarborough (1962), y los manuales de lucha contrainsurgente. Así las Fuerzas Militares hicieron estudios de los líderes guerrilleros y de los hombres más cercanos. Para ello se infiltraron agentes encubiertos en las bandas (HENDERSON, 2006). Los agentes infiltrados hacían parte del grupo de inteligencia y localización-GIL, creado en 1963 con el fin de diseñar tácticas para enfrentar a los focos guerrilleros. La estrategia delineada por el GIL, decía el Teniente Coronel José Joaquín Matallana, preveía el combate en grupos pequeños, de hombres bien entrenados y dotados, con acciones rápidas y certeras (ARANGO, 1984). Las labores de inteligencia del GIL permitieron identificar que:

El movimiento agrario de Marquetalia contaba dentro de su organización con guerrillas muy bien organizadas y armadas con efectivos que han sido calculados en 450 hombres con fusiles ametralladores, carabinas, fusiles, pistolas, revólveres, granadas de fabricación casera y algunos de tipo MK-II (RoJas Delgado ET AL., 2017).

Tanto las acciones cívicas, como las de inteligencia en la lucha contrainsurgente en Colombia, iniciando la década de 1960, modificaron las Fuerzas Militares en distintos niveles. El Plan Lazo trajo consigo lo que se conoció como el "Nuevo método operacional", que obligó a las Fuerzas militares a capacitar de una nueva manera a los hombres para afrontar los nuevos retos que enfrentarían. El énfasis recibido por los militares fue en tácticas de la guerra irregular. Así, fuera de la instrucción puramente de combate, todo el personal militar recibió un adoctrinamiento especial sobre trato a personal civil, acción cívica y acción sicológica (Nuevo MÉTODO OPERACIONAL, 1963). Así mismo, la formulación del Plan Lazo tuvo amplias repercusiones ideológicas y organizativas en las Fuerzas Militares. En el plano ideológico se dio vía libre al anticomunismo como directriz para la identificación 
de un nuevo "enemigo", categoría central de toda misión militar. Las publicaciones militares introdujeron conceptos novedosos, como el de "seguridad interna", complementario al de seguridad nacional, además de "guerra irregular", "operaciones psicológicas" y "acción cívica”. En la Escuela Superior de Guerra comenzaron a estudiarse los problemas de la posguerra, sobre la base de una concepción de dos bloques antagónicos (Leal, 2002; Rojas Delgado et aL., 2017; Torres, 2000).

Esas transformaciones, de los llamados militares reformistas, cayeron mal en algunos sectores de las Fuerzas Militares, sobre todo en aquellos más conservadores. El Plan Lazo, en cabeza de los reformadores, dejaba en un segundo plano las acciones militares, primando los programas sociales para erradicar el comunismo del país (LEAL, 1994). Los reformistas se distinguieron de las anteriores generaciones de oficiales conservadores, ya que incluyeron un análisis social profundo en el despliegue institucional de la doctrina de la Seguridad Nacional, buscando las causas profundas de la violencia; tratando de erradicarlas para alcanzar la paz. Por ello, entre otras causas, los reformistas fueron conocidos como "soldados-intelectuales" y "ovejas negras" (DUFORT, 2013). Esas visiones y perspectivas iban en contravía de la tradición castrense prusiana, encarnada por los sectores conservadores, que resultaron ser la mayoría de los cuerpos de oficiales (CAKE, 2009).

Así mismo, algunos políticos conservadores se manifestaron en contra del Plan Lazo y de su débil forma de enfrentar a los bandoleros comunistas. El congresista Álvaro Gómez Hurtado fue el principal detractor de la "indiferencia e insensibilidad" con que se trataba el tema. Desde octubre de 1961, el Senador denunció el establecimiento de "repúblicas independientes". Ese término correspondía a ciertas zonas controladas por grupos de guerrillas campesinas, sobrevivientes a la violencia de la década de 1950 y que no se acogieron a la amnistía propuesta por Rojas Pinilla (COMisión NACIONAL de REPARACIÓN Y RECONCILIACIÓN, 2013; Pataquiva, 2009; Pecaut, 2008; Rojas Delgado Et Al., 2017). Entre las repúblicas independientes se podían contar las de Tequendama, Urabá, Vichada, Territorio Vásquez, El Duda, Ariari, Guayabero, Pato, Río Chiquito y Marquetalia (Alape, 1985; MarulandA, 2003). 
Para Gómez Hurtado, las repúblicas independientes atentaban contra el poder efectivo del Estado en todo el territorio, por lo que debían ser atacadas. El Congresista así lo expresó:

El Gobierno tolera a las "repúblicas independientes" librando contra ellas una miserable acción de periferia y limitándose a mantener los puestos de guardia, en donde la rutina termina por liquidar la disciplina militar; en donde más bien se vuelve un problema la convivencia de los militares con los civiles, porque un militar que no está ocupado en algo se vuelve una fuerza disolvente. Un militar que está viviendo simplemente, sin trabajo, en una función estéril de vigilar a nadie, se desmoraliza y se perturba la moral de las Fuerzas Armadas. En el pasado, los militares entraban en condiciones malas o buenas, con elementos o sin ellos, sin miedo de incomunicación, con armas o sin armas, pero libraban una batalla contra las personas que estaban desconociendo la soberanía Nacional. Ahora este primer gobierno del Frente Nacional, no hace sino tolerar las 'repúblicas independientes (VILlamizar, 2017).

Estas afirmaciones coincidían con algunas declaraciones del General Prada Fonseca, jefe del Estado Mayor del Ejército. El General, refiriéndose particularmente a la república independiente de Marquetalia, decía que aquella se podría convertir en una especie de Segunda Sierra Maestra (Centro Nacional de Memoria Histórica, 2013; Moreno Mancera, 2014). Esas diferentes manifestaciones, tanto de militares como de políticos conservadores, contra las repúblicas independientes y la forma en la que estaban siendo enfrentadas llevaron a una modificación de la estrategia del gobierno de León Valencia. Iniciando 1964, el "Presidente de la Paz", como era conocido, anunció públicamente que antes de terminar ese año estarían ya exterminadas las repúblicas independientes (PIZARRo, 1991).

Cuando los altos mandos militares y el Gobierno anunciaron el inicio de la operación Marquetalia algunos sectores de la prensa de la capital la apoyaron de manera enfática. El Espectador, por ejemplo, proclamó el eslogan del "año de la extinción" emitido por León Valencia. Dentro de los argumentos del periódico para apoyar la operación militar estaba el miedo a la instalación del comunismo en el sur del país, desde donde se podría extender (Marquetalia, EPicentro del Plan, 1964). La comparación hecha por el General Prada Fonseca, que Marquetalia podría convertirse en una Segunda Sierra Maestra había motivado el apoyo 
incondicional de diferentes sectores de la sociedad en la incursión a la zona controlada por los comunistas al sur del Tolima (KROENER, 2017).

Las acciones cívicas planteadas en el Plan Lazo, que recogían buena parte de las tendencias globales de la lucha contrainsurgente y que tuvo un impacto para retirar el apoyo de las comunidades a las guerrillas comunistas en diferentes contextos alrededor del mundo, no fue aprobado por los militares y políticos conservadores. Estos sectores entendían que la manera más efectiva para enfrentar a los bandoleros era por medio de los preceptos de la guerra prusiana y no veían con buenos ojos alguna modificación a ese tipo de guerra (NiETO, 2014; PiZARro LeONGóMEZ, 1987). Así fue que los militares reformadores fueron derrotados en la arena política. El General Ruiz Novoa fue separado del Ministerio de Guerra en 1965 por cuestionamientos al Gobierno sobre la ayuda ineficaz de la autoridad civil a la acción cívica y, además, por la falta de reformas estructurales necesarias en el campo, sobre todo la reforma agraria. El presidente Valencia temía un nuevo golpe de Estado (DuFORT, 2013; Leal, 2002). Con la salida del General Ruiz Novoa del Ministerio, el Plan Lazo perdió dinamismo y cualquier referencia a él resultaba mal vista en las Fuerzas Militares. El nuevo ministro de Guerra, el General Gabriel Rebeiz Pizarro, abandonó la acción cívico militar para concentrarse en operaciones netamente militares (DUFORT, 2013).

\section{LA OPERACIÓN SOBERANÍA Y LAS ACCIONES MILITARES EN MARQUETALIA}

Ante la falta de compromiso por parte de las autoridades civiles para mantener las acciones cívicas y del rechazo de los sectores conservadores de las Fuerzas Militares y de la política, las operaciones militares tuvieron un rol principal en la lucha contrainsurgente en Colombia a partir de 1964. La represión militar estuvo precedida por la campaña de denuncias de Gómez Hurtado contra las repúblicas independientes y la pasividad del Gobierno contra esos centros del comunismo que se escapaban del control estatal (COMISIÓN NACIONAL DE REPARACIÓN Y RECONCILIACIÓN, 2013).

Además de la presión de los sectores conservadores, las acciones de los grupos guerrilleros también motivaron a que las acciones militares 
dieran inicio. Finalizando 1963, la cuadrilla de Pedro Antonio Marín atacó una columna de abastecimientos, dando muerte a los soldados arrieros. La cuadrilla robó las mulas y sus cargas. Ese grupo también derribó una avioneta de Aerotaxi que cubría la ruta Planadas-Neiva y secuestró a los pilotos. Este se convirtió en los primeros secuestros que se auto atribuían las cuadrillas de Pedro Antonio Marín. Luego los guerrilleros dieron muerte a dos oficiales de la Fuerza Aérea Colombiana que acudieron al rescate de la tripulación en un helicóptero (AlaPE, 1989; VALENCIA Tovar, 1992). Asimismo, iniciando 1964, la cuadrilla al mando de alias 'Richard' ejerció presión sobre la población de la región, buscando el apoyo solidario de los pobladores con la guerrillerada de Marquetalia. En esa búsqueda asesinaron a quienes se resistían (VALENCIA TovAR, 2009). Así, desde enero de 1964, el Gobierno y las Fuerzas Militares iniciaron la preparación para retomar el control sobre la zona de Marquetalia.

Entonces, luego de la etapa cívico militar, la última etapa para la restauración del Estado en Marquetalia sería de carácter netamente militar. Para llevar a cabo la Operación Marquetalia, desde enero de 1964, diferentes instituciones y agencias gubernamentales trabajaron de manera conjunta (Comienza el Plan Marquetalia, 1964). Las operaciones fueron organizadas de acuerdo a la información recolectada por el GIL y así se desplegaron cerca de 2.500 soldados alrededor de la zona de Marquetalia.

Cabe resaltar que las versiones de las Fuerzas Militares y de los insurgentes son diferentes. Cada una de las partes enfrentadas construyó un relato de la Operación Marquetalia de acuerdo a sus conveniencias. Los primeros buscando resaltar la superioridad militar de las Fuerzas y la manera como llevaron el Estado a una zona llena de forajidos. Mientras que los insurgentes hicieron de la derrota sufrida en Marquetalia una victoria moral que les serviría como mito fundacional, en el que algunos datos y relatos fueron maximizados para mostrar como heroica la resistencia campesina sobre las fuerzas del Estado (Olave, 2013; VezzetTi, 2009). Esta versión guerrillera fue vista por las Fuerzas Militares como una leyenda negativa que alimentó el mito fundacional de las FARC-EP y mostraba todas las pericias contra las injustas acciones militares en su contra (VALENCIA Tovar, 1992). 
La responsabilidad estratégica de la Operación fue encomendada al comandante de la VI Brigada, Coronel Hernando Currea Cubides, con la participación de los batallones Tenerife (desplazado desde Neiva), Caycedo y Boyacá (desplazados desde Pasto), Roock y Vencedores, y las compañías especializadas en acciones contraguerrilleras Rifles, Flecha y Arpón. De igual forma se desplazaron las recién fundadas Unidades del GIL, al mando del Capitán Augusto Padilla. Los responsables operativos fueron el Teniente Coronel José Joaquín Matallana, al mando del batallón Colombia, y el coronel Armando Pinzón Caicedo, con asistencia táctica de militares estadounidenses (NO HAY INVASIÓN MILITAR, 1964; Pizarro, 1991; Rojas Delgado Et Al., 2017; Valencia Tovar, 1992). Según los planes trazados por los altos mandos militares, la Operación debía ejecutarse mediante la acción conjunta y simultánea de batallones, apoyados por la Fuerza Aérea y la Policía Nacional; eso da un total aproximado de 2.400 hombres en toda la operación ${ }^{6}$ (ARANGO, 1984; Ferro, Medina, \& URibe, 2002; Marquetalia 35 aÑos DesPuÉs, 1999).

Por su parte, los campesinos de Marquetalia decían conocer que el plan del Ejército contra la región de Marquetalia tenía previsto atacar militarmente la zona de Marquetalia en la tercera semana de mayo de 1964. Para esa operación utilizarían 16.000 soldados: fuerzas combinadas de infantería, artillería, así como la aviación para bombardeos y aerotransporte, junto con el apoyo y asesoría de la Misión Militar estadounidense y los Cuerpos de paz estadounidenses. También decían conocer que emplearía en todo su rigor la táctica del cerco y el bloqueo, y "si se producía por parte de los campesinos alguna manifestación de resistencia, serían lanzadas bacterias contra la población" una especie de guerra biológica o empleo de armas biológicas (ARENAS, 2000; MARULANDA, 2003; SANTRICH, s.f.; URIBE, 2007).

Los batallones comprometidos con la operación militar estaban encargados de recolectar información que les permitiera ubicar las cuadrillas de los disidentes. Posteriormente usaban pequeñas unidades del GIL que, una vez procesada la información, estaban encargadas de acercarse a los campamentos subversivos para refinar la información

\footnotetext{
6 El Coronel Matallana afirmaba que ese número correspondía a casi la tercera parte del Ejército en ese año (ARANGo, 1984).
} 
obtenida. La intención era cerrar todas las vías de escape para bloquear cualquier tipo de huida; con los demás batallones presionar a las estructuras para impedir cualquier tipo de apoyo y crear un cerco para neutralizar el accionar de las cuadrillas de Pedro Antonio Marín, que abarcaba una zona de más de 5.000 kilómetros cuadrados (DomINAMOS 4 QUinTAS PARTES DE MARQUETALIA, 1964).

La Operación Marquetalia (Soberanía) en un principio contaba con cuatro fases:

1. Concentración de tropas

2. Aislamiento del objetivo asignado a la Sexta Brigada

3. Operaciones de cerco y destrucción

4. Consolidación

Las dos primeras fases, concernientes a la preparación de las unidades para el desarrollo de la Operación, se llevaron a cabo desde inicios de 1964. La primera fase, de agrupación de tropas y medios logísticos, estuvo acompañada de información a la opinión pública sobre la necesidad e importancia de la misma. La segunda fase, que preveía la penetración de la zona de Marquetalia y su aislamiento, fue encargada al Coronel Currea Cubides, quien designó a los batallones Boyacá, Rooke y Tenerife, con un total aproximado de 1.500 hombres, para llevar a cabo la misión. La orden era cubrir la región de Gaitania, Planadas, Órganos, Aipecito, San Luis, Aleluya y el Carmen, Tolima, una superficie de 5.000 kilómetros cuadrados. Esta actividad debían desarrollarla mediante la táctica de líneas exteriores, concentrándose en un área externa, para ingresar al sur del Tolima (Rojas Delgado Et Al., 2017; Ugarriza \& Pabón, 2017).

El desarrollo de la tercera fase resultó más complicado que lo estipulado por los altos mandos militares. El punto central fue el uso de las minas antipersonales por parte de las cuadrillas campesinas. Esas minas tenían varios objetivos tácticos en el desarrollo de la guerra irregular, planteada ya por esa estructura, tales como el retardo de las operaciones, brindar seguridad en sus áreas y un efecto psicológico desmoralizante en el soldado. Lo anterior ya había sido descrito por Saloth Sar, más conocido como Pol Pot, a quien, como líder de los 
Jemeres Rojos en Camboya, se le atribuye la frase "Una mina es un soldado perfecto: no necesita comida ni agua, no tiene sueldo ni descanso, y espera a su víctima por 30 años o más”. De esta manera, Pedro Antonio Marín combinaba el uso de las minas antipersonales con la realización de emboscadas (EMBOSCADAS, CAMPOS MINADOS Y PENA DE MUERTE ENCUENTRA EL EJÉRCITO, 1964).

Las operaciones militares iniciaron el 18 de mayo de 1964 y el primer enfrentamiento fue en el cañón del río Atá (BEHAR, 1988). El 27 de ese mes, las tropas del Ejército se enfrentaron contra una cuadrilla de campesinos, fecha importante en el mito de fundación de las FARC-EP. El enfrentamiento favoreció apabullantemente a los insurgentes. Estos mostraron su pericia en las tácticas de guerra móvil y guerra de guerrillas que, junto con las minas antipersona, hicieron retroceder a los militares (ARENAS, 2000; SANTRICH, s.f.). Ese primer revés obligó a las Fuerzas Militares a replantear su acceso a la zona donde se encontraba la fortaleza de Pedro Antonio Marín, Hernando González, Luis Alberto Morantes e Isauro Yosa (AlAPE, 1985; ARANGO, 1984).

La dificultad del terreno de la región de Marquetalia, el uso de minas y la superioridad táctica de los guerrilleros hicieron que la fase de cerco y destrucción tuviera que ser replanteada (ARANGO, 1984). El cambio en las operaciones militares requirió de la experiencia del batallón Colombia, que se encontraba adelantando acciones contrainsurgentes al norte de Tolima. La entrada del batallón a la Operación fue en junio de 1964. El Teniente Coronel José Joaquín Matallana, quien lo comandaba, analizó fotografías aéreas para poder planear la estrategia ideal y entrar a Marquetalia. Las fotografías fueron tomadas con la colaboración de agentes estadounidenses desde una gran altura "porque la defensa que tenían los guerrilleros en ese punto era tal, que los aviones no podían volar a menos de dos mil metros de altura" (ARANGO, 1984).

El entonces Coronel Matallana describió los detalles de la Operación planeada conjuntamente con el Coronel Correa Cubides:

Mi operación consistía en que se trasladaría por aire unos doscientos cincuenta hombres del Batallón Colombia, organizados en los grupos de combate, excelentes tiradores y sumamente hábiles para lanzarse desde 
el helicóptero, inclusive desde alturas inverosímiles (...) Eran capaces de lanzarse desde un helicóptero a alturas mayores de quince metros sin que les pasara nada en sus piernas (...) El personal lo trasladé a Neiva en aviones DC-3 o C-477 que llamamos militarmente (...) Necesitaba una tripulación muy hábil. Además, los accesos a esa población [Marquetalia], un cañón muy feo y que terminaba justamente en una loma donde estaba ubicado el cementerio (ARANGO, 1984).

El comandante de la flotilla de helicópteros de la FAC, Capitán Belarmino Pinilla, a su vez describía la operación:

Habíamos construido una base para helicópteros en la cordillera, donde congregamos la tropa de asalto, unos 400 hombres. Para esa operación utilizamos cuatro helicópteros: dos Iraquois y dos Kaman de giro entremezclado. Acordamos hacer un circuito elíptico que recorríamos a prudente distancia. Las máquinas cargaban y descargaban alternativamente la tropa (MOLANO, 2017).

La operación aerotransportada del 14 de junio de 1964 estuvo precedida por un ataque armado en las montañas para facilitar el descenso de los militares. Al respecto, 'Jacobo Arenas' describe esa de esta manera:

El sábado 14 de junio, a las 8:05 de la mañana, los "filos" colindantes del altiplano de Marquetalia, sobre puntos analizados por la observación aérea, fueron bombardeados con proyectiles cohetes. Cada filo fue objetivo de 30 proyectiles de alto poder; 8 proyectiles cayeron en el pequeño altiplano, muy cerca del poblado, y 15 sobre un pequeño terraplén donde era visible un portón de madera. El bombardeo iba acompañado de fuego aéreo de ametralladoras punto 50 (ARENAS, 2000).

Dos aviones tipo T-33 ${ }^{8}$ hicieron dos pasadas sobre la región, disparando cohetes y ametrallando objetivos identificados aéreamente de manera previa (ArANGO, 1984). Para el Coronel Matallana, la acción aérea fue básicamente "sicológica y no destructiva" (AlAPE, 1985,).

Estas aeronaves llegaron a Colombia en 1944, el gobierno de Colombia adquirió 30 aeronaves de este tipo.

$8 \quad$ La FAC recibió estás aeronaves en 1954, 
Las acciones del 14 de junio motivaron la llamada leyenda negra. Es a partir de este momento que las versiones de ambas partes en conflicto difieren de manera más sustancial. Los principales desacuerdos tienen que ver con la manera en que entraron las Fuerzas Militares a la región, el número de combatientes por cada una de las partes y con algunas demandas de "guerra sucia" por parte de los militares contra las cuadrillas y la población de la región de Marquetalia.

Entre los principales asuntos sobre los que se construyó esa leyenda fue sobre la cantidad de elementos dispuestos para iniciar la Operación. Como ya se dijo, el número de combatientes por bandos varía según la versión. Los militares afirmaron que la Operación contó con cerca de 2.500 hombres en total para poder cercar la zona, y que esos hombres se enfrentaron con aproximadamente 250 guerrilleros (URIBE, 2007). Por su parte, del lado de los campesinos se extendió la versión que el ataque contra Marquetalia había sido perpetrado por 16.000 soldados y que ellos no llegaban a los 50 campesinos armados, con poco más que algún fusil y pocas ametralladoras (AlAPE, 1985; ArENAS, 2000; SANTrich, s.f.). Este relato resultó central en la narrativa fariana, en tanto que mostraba la proeza de un grupo de campesinos que se enfrentó de manera desigual ante todo el poder logístico y bélico del Ejército colombiano.

El principal elemento de la leyenda negra fue el referente a la mañana del 14 de junio de 1964 y los días subsiguientes. Los relatos de esa mañana coinciden en que hubo aviones bombarderos que atacaron puntos específicos en la zona. Sin embargo, ellos difieren en detalles tales como el poder de las bombas. Mientras que 'Tirofijo' denunció el uso de bombas de cinco toneladas, basado en el tamaño de los cráteres generados (ALAPE, 1989), la Fuerza Aérea Colombiana contaba, para ese momento, con dos bombarderos capaces de actuar en la Operación Marquetalia: "el viejo B-26 de la II Guerra Mundial, con capacidad de lanzar artefactos hasta de 250 kilogramos y los T-33 con perchas para ocho bombas de $20 \mathrm{~kg}$ o hasta dos de 250" (VALENCIA Tovar, 1992). El relato de 'Tirofijo' parece salido de proporciones a la luz de la tecnología disponible por las Fuerzas Militares para el momento mismo de la Operación, que distaba de contar con aeronaves capaces de hacer el daño denunciado por los guerrilleros. 
El ataque aéreo fue una parte de la construcción de esa leyenda. El relato continuó y, en palabas del líder guerrillero 'Olimpo', "cuando ya el enemigo se convenció de la inefectividad de su fuego aéreo entonces nos arrojaron bombas biológicas, infecciones mortíferas. Primero nos lanzaron una epidemia de gastroenteritis, y después una de viruela negra" (ARANGO, 1984). Esta versión se encuentra también en los relatos y testimonios de diferentes líderes guerrilleros (AlaPE, 1985; ARENAS, 2000; PIZARRO, 1991; SANTRICH, s.f.) y de publicaciones que denunciaron el uso de armas bacteriológicas (VILlEgas ARANGO, 1974). Al respecto, 'Tirofijo' envió una carta a la Cruz Roja Colombiana denunciando el uso de agentes bacteriológicos en la Operación Marquetalia. En la carta, el líder guerrillero describe los síntomas de las enfermedades que denominaron como "viruela negra" y "espuela de gallo":

"Contra la masa campesina, señores de la Cruz Roja Nacional, fueron lanzadas bacterias de viruela y otras bacterias que causan grave enfermedad [sic] en los talones de los pies. Es tal el poder de las bacterias que las bestias las están sufriendo en el cuerpo y en los talones de los cascos. Aquí hemos bautizado estas enfermedades con los nombres de "viruela negra" y "espuela de gallo". La viruela negra comienza afectando las partes más sensibles del cuerpo. Es una ampolla negra que produce un líquido que deja, al correrse por la piel, vetas negras. Los síntomas de la enfermedad se producen así: vómito, intenso dolor de cabeza, fiebre alta y escalofríos intensos. Al día siguiente la gente amanece con ampollas en todo el cuerpo. Hay casos en que encontramos una tupida presencia de viruela, semejante a la viruela común. La viruela es de color negro concentrado. A los cinco días la viruela comienza a secar y la materia que ella produce en su proceso de crecimiento y maduración taladra la carne produciendo en siete días más, profundos hoyitos pestilentes".

"La espuela de gallo" es una ampolla, también de color negro, concentrado, que comienza a producir un dolor intenso en el lugar del pie donde más tarde hará presencia. Lo general es su aparición en los talones de los pies. Comienza con un fuerte dolor en lo profundo del talón. La gente tiene que andar en puntillas. Los síntomas de la "Espuela de Gallo" son fiebre alta y vómito. Hay casos en que produce fuertes diarreas (...) Hemos usado antibióticos de alta concentración. Hemos cambiado diariamente de ubicación, hemos resuelto no volver a beber agua, hemos aislado a los enfermos, pero la "viruela y la espuela de gallo" nos persiguen como una sombra. Las bacterias, señores de la Cruz Roja, han penetrado la selva. 
Así piensa nuestro gobierno someter a las fuerzas de la oposición. Pero no podrá (COMBATIR LOS EFECTOS DE GUERRA BACTERIANA SOLICITAN LOS COMBATIENTES A LA CRUZ RoJa, 1964).

Las palabras de 'Tirofijo', denunciando el uso de armas bacteriológicas, se suman a otras denuncias hechas en diferentes publicaciones que relatan la forma en la que se presentó el ataque bacteriológico. El periódico Voz proletaria, adepto al Partido Comunista Colombiano, denunció el uso de una "guerra bacteriológica" que fue catalogado como un crimen contra los 5.000 habitantes de la región (ESTAMOS EN LA RESISTENCIA CONTRA LA OPRESIÓN, DICEN CAMPESINAS DE MARQUETALIA, 1964; No DESTRUIRÁN A Marquetalia, 1964).

Por su parte, 'Jacobo Arenas' (2000) relata cómo las bacterias fueron lanzadas por aviones "yanquis" y la manera como buscaron combatirlas, pidiendo ayuda a los revolucionarios en la ciudad. Incluso una estrofa del corrido La Marquetalia habla al respecto:

Cómo olvidar la tragedia

De las familias marchando

Por trochas seguían silbando

Los niños y las bacterias

El hambre que los asedia

Desplazados en el tiempo

Es gente que sigue huyendo

De las bombas infernales

Que incendian los maizales,

Las finquitas y el sustento (Centro Nacional de Memoria HistóRICA, 2013)

Alias 'Olimpo' también se refirió al respecto en una entrevista (ArAngo, 1984), con un poco más de detalle, ya que él fue uno de los principales encargados de tratar a los enfermos. 'Olimpo' relata cómo, a partir de conocimientos que tenía de "los experimentos de Pasteur" logró reducir los estragos de la "viruela negra". "Hacía hervir leche de vaca y la dejaba reposar hasta la temperatura normal del cuerpo humano. 
Con aguja hipodérmica inyectaba un centímetro, por vía intramuscular"; luego, cuando las ampollas se secaban, se realizaba un baño con boñiga hervida en agua, haciendo una combinación entre los avances de la ciencia moderna y la medicina popular que, según 'Olimpo', resultó efectiva.

Si bien es cierto que el relato de la "viruela negra" muestra, efectivamente, una serie de complicaciones médicas que afrontaron los combatientes y civiles que acompañaban las cuadrillas, esa denominación, adoptada por ellos, puede reflejar otra realidad, de acuerdo con los datos oficiales del momento. Las cifras sobre casos de viruela, reportadas por el Gobierno colombiano, muestran un constante descenso desde 1955, llegando a erradicarla por completo en 1967. Ahora bien, en los años de 1964 y 1965 hubo un incremento importante, reportándose 21 y 149 casos, respectivamente (RoDRIGUES, 1975). Desagregados, esos casos en 1964, se presentaron brotes del virus en Istmina (Chocó) Sincelejo (Sucre) y Mitú (Vaupés) (World Health Organization, 1964b, 1964a). Para 1965, cuando hubo un crecimiento importante en los casos reportados de viruela, los principales focos en los que se presentaron fueron en Antioquia, Atlántico, Bolívar, Caldas, Cauca, Chocó, Huila, Córdoba y Norte de Santander, Santander y Valle del Cauca (World Health Organization, 1965b, 1965a, 1965c).

Ahora bien, la zona de Marquetalia durante años estuvo fuera del control del Gobierno central, y por tanto cabría la posibilidad de que los datos de posibles brotes de viruela no entraran dentro del registro nacional. Sin embargo, las denuncias de ataques bacteriológicos fueron posteriores a la toma por parte de las Fuerzas Militares de aquella zona. Cabe apuntar que la supervivencia del virus de la viruela en el aire es relativa a la temperatura y la humedad del ambiente; a mayor temperatura, menor es su tiempo de vida; es poco resistente a la luz solar, rayos ultravioleta y desecación (GESTAL, 2005). La zona de Marquetalia se encuentra a una altura promedio de $1.200 \mathrm{msnm}$ y a una temperatura promedio superior a $\operatorname{los} 25^{\circ} \mathrm{C}$, ambiente en el que la viruela no podría sobrevivir más de 24 horas. Sin embargo, es importante tener en cuenta la dificultad de identificar los ataques biológicos de epidemias naturales o de brotes de alguna otra enfermedad que pueda ser asociada con ellos (BARRAS \& Greub, 2014). Precisamente, parece 
ser este último el caso. Los campesinos insurgentes en las montañas de la zona de Marquetalia pudieron haber asociado los síntomas de una posible epidemia o alguna bacteria propias de la región. Esto se puede suponer a partir de los testimonios antes referenciados. En ellos, los guerrilleros afirman que "aquí hemos bautizado estas enfermedades con los nombres de "viruela negra" y "espuela de gallo", sin embargo, los síntomas difieren de los propios de la viruela, sobre todo en lo referente a las erupciones puntiformes presentes en la última (BAZIN, 2000; BRAS, 1952), en contraste con las ampollas negras y pestilentes de los relatos de los guerrilleros.

Esta asociación de los síntomas padecidos en Marquetalia con la viruela, particularmente lo que ellos llamaron "viruela negra", permite ver precisamente una conexión entre las experiencias de los guerrilleros con discursos globales, más allá de los relacionados con el comunismo y el contexto de la Guerra Fría ya ampliamente debatidos (OFFSTEIN \& AristizÁbal, 2017; Penagos, 2013; Trejos, 2015; Trejos \& GonZÁlez, 2013). Los grupos de campesinos rebeldes en las montañas de Marquetalia pudieron haber hecho uso del discurso circulante en contra de la viruela en el mundo, que era mostrada como una enfermedad mortal y la adaptaron a su realidad con el objetivo de poder mostrar a la comunidad internacional la lucha que libraban contra el Estado. En ese mismo sentido, la carta a la Cruz Roja refuerza ese presupuesto, en tanto que al ser un organismo internacional, el llamado a su mediación permite visibilizar el conflicto de una manera que fuera benévola para ellos mismos, mostrando la "guerra injusta" que el Gobierno adelanta en Marquetalia.

El contraste de los relatos de ambas partes resulta importante y daría para pensar que no se trata de algunos posibles errores de apreciación, sino que tiene que ver con la intencionalidad con la que se construyeron los reportes. Los números y relatos presentados por las FARC-EP parecería que tienen que ver con una "retórica exaltada de la guerra" (VEzzetTi, 2009), en la que se presentaron los hechos como una gesta de proporciones épicas, en la que unos pocos campesinos desarmados se enfrentaron de manera desigual contra todo el poder logístico y bélico del Ejército colombiano. Esta es una fórmula utilizada en otras latitudes y en otros periodos de la historia con el objetivo de generar 
una cohesión de grupo alrededor de relatos que no siempre se acercan a la realidad ${ }^{9}$ (MACKENZIE, 2007).

\section{CONCLUSIÓN}

Con el fin de la Segunda Guerra Mundial, la guerra entre Estados pasó a un segundo lugar, para presenciar la emergencia de una serie de conflictos internos, que tuvieron como escenario la descolonización en Asia y África y el expansionismo comunista. Durante esos conflictos, los Estados Unidos tuvieron un rol importante, transmitiendo las tácticas de la guerra contrainsurgente y un fuerte componente cívico militar. Colombia fue un escenario de ese tipo de conflicto, donde se implementaron ese tipo de tácticas, haciendo parte de la geografía global del combate. Esto se logró, principalmente, por la participación de unidades militares en escenarios, como la Guerra de Corea, donde el intercambio de conocimientos entre personas de todo el mundo dio como resultado la proliferación de las tácticas contrainsurgentes y su posterior adaptación dentro de la geografía global del combate.

Para el caso colombiano, las tácticas contrainsurgentes se manifestaron en el Plan Lazo, redactado por el General Ruiz Novoa, quién fue comandante del batallón $n^{\circ} 1$. Colombia en la guerra de Corea participante en la Guerra de Corea. Gracias a ese plan se importó la idea de combatir las problemáticas de la población civil para ganarse sus simpatías a partir de obras públicas, programas de educación, salud, entre otros. Los avances del Plan Lazo se interrumpieron por militares y políticos conservadores que buscaban que se usara mano dura contra los guerrilleros. De ese modo se pueden ver las tensiones entre los discursos y el conocimiento global contra las dinámicas e instituciones globales, tensión que no se pudo negociar y, al contrario, trajo consigo el fin de las tácticas cívico militares y abrió paso a la confrontación armada. Entonces, se puede afirmar que pese a que Colombia hacía parte de una geografía global del combate, la idiosincrasia de un sector de la sociedad impedía que se

Mackenzie (2007) dice que el relato de fundación fariano "será una variante colombiana de la leyenda fabricada en 1945 por el Partido Comunista Francés sobre 'el partido de los 75.000 fusilados', tan apreciada por Maurice Thorez, el desertor de 1940, amnistiado tras la liberación por el general De Gaulle". 
pudiera sacar provecho de los avances tácticos a nivel global de la lucha contrainsurgente para volver al modelo prusiano, que ya estaba arraigado dentro de las Fuerzas Militares del país.

Así mismo, este análisis muestra cómo las Fuerzas Militares actuaron de manera conjunta contra la insurgencia, tanto en las acciones cívico militares, como en la Operación Soberanía. Como se dijo, las acciones cívico militares movilizaron a diferentes sectores del aparato estatal y de las Fuerzas Militares. El Ejército, la Fuerza Aérea, la Policía e incluso la Armada realizaron acciones para ganarse la simpatía de las poblaciones que tendían a radicalizarse. Precisamente fueron ellos quienes se encargaron de la construcción de caminos y, además, gracias a la logística y al transporte de la Fuerza Aérea y de la Armada se pudo llegar a lugares inaccesibles, y después, mantener el aporte logístico para el sostenimiento de las operaciones en el territorio, así como brindar movilidad, dada la ausencia de vías terrestres donde realizaron brigadas educativas y de salud. Por otro lado, en cuanto a la Operación Soberanía, la acción de la Fuerza Aérea fue crucial, precisamente para lograr acceder a lugares estratégicos y alcanzar la victoria en la toma Marquetalia.

Así como ya se probó que las Fuerzas Militares estaban insertas en un contexto global de la lucha contrainsurgente que ubicaban al país dentro de una geografía global del combate, los guerrilleros también se encontraban en esta red de circulación de discursos de carácter global. El avance del comunismo en el mundo y particularmente en Latinoamérica se ubica al tope de esos discursos globales, pero en la última parte del capítulo se quiso mostrar un caso más sobre el que faltaría profundizar. Los campesinos subversivos de Marquetalia hicieron uso del discurso global de la erradicación de la viruela, que en la década de 1960 estaba en auge. Ese uso discursivo sirvió para que ellos mismos mostraran al mundo el conflicto con el Estado de una manera desigual e injusta, magnificando algunos detalles, buscando exaltar la resistencia que ese grupo guerrillero presentó en 1964.

Este estudio abre la puerta para seguir preguntándose por esas conexiones globales, no solo de la oficialidad, sino también de los grupos guerrilleros en las montañas de Colombia. A primera vista parece que 
fueran pocos, pero la investigación reciente ha permitido sacar a la luz algunos enlaces de carácter global que se manifestaron en las prácticas y discursos guerrilleros desde la década de 1960.

\section{REFERENCIAS}

Alape, A. (1985). La Paz, La Violencia: Testigos de Excepción. Bogotá: Planeta.

Alape, A. (1989). Tirofijo: Las vidas de Pedro Antonio Marín, Manuel Marulanda Vélez (Edición: 1a Edición). Bogotá: Planeta.

Alianza para el Progreso. (1961). Alianza para el progreso. Documentos básicos.

ArAngo, C. (1984). FARC, veinte años: De Marquetalia a La Uribe. Ediciones Aurora.

Arenas, J. (2000). Diario de la resistencia de Marquetalia. S.1.

AtehortúA, A. (2008). Colombia en la guerra de Corea. Folios, (27), 63-76.

Aviles, W. (2006). Global Capitalism, Democracy, and Civil-Military Relations in Colombia (Annotated edition edition). Albany: SUNY Press.

BArber, W. F. R. (1966). Internal Security and Military Power: Counterinsurgency and Civic Action in Latin America by Willard F. Barber and C. Neale Ronning (First Edition edition). Columbus : Ohio State University Press.

Barras, V., \& Greub, G. (2014). History of biological warfare and bioterrorism. Clinical Microbiology and Infection, 20(6), 497-502. Recuperado de: https://doi.org/10.1111/1469-0691.12706

BAZIN, H. (2000). The Eradication of Smallpox. Elsevier.

BeHar, O. (1988). Las guerras de la paz. Planeta.

Bras, G. (1952). The Morbid Anatomy of Smallpox. Documenta de Medicina Geographica et Tropica, 4(4), 303-351. 
CAKE, T. S. (2009). The impact of military culture and doctrine on Colombia's counterinsurgency (Tesis de Maestría). Universidad de Calgary.

Campesinos apoyan a las FF.AA. (1964, mayo 24). El Espectador.

Centro Nacional de Memoria Histórica. (2013). Guerrilla y población civil trayectoria de las FARC 1949-2013. Bogotá: Imprenta Nacional.

Combatir los efectos de guerra bacteriana solicitan los combatientes a la Cruz Roja. (1964, agosto 13). Voz proletaria.

Comienza el Plan Marquetalia. (1964, mayo 18). El Tiempo.

Comisión Nacional de Reparación y Reconciliación (Ed.). (2013). ¡Basta ya! Colombia, memorias de guerra y dignidad: Informe general (Segunda edición corregida). Bogotá: Centro Nacional de Memoria Histórica.

Damms, R. V. (2019). Dwight D. Eisenhower and American Foreign Policy. Oxford Research Encyclopedia of American History. Recuperado de: https://doi.org/10.1093/acrefore/9780199329175.013.750

Dominamos 4 quintas partes de Marquetalia. (1964, junio 21). El Espectador.

Doney, J. (1966). A Study of United States Support of Civic Action in Colombia (Tesis de Maestría). University of Southern California, Los Angeles.

Duara, P. (2004). Decolonization: Perspectives from now and then. London; New York: Routledge.

Dufort, P. (2013). Las políticas desarrollistas de Alberto Ruiz Novoa a principios de 1960: ¿Se podría haber evitado medio siglo de guerra? Estudios en Seguridad y Defensa, 8(16), 31-46. Recuperado de: https:// doi.org/10.25062/1900-8325.74

Edison, D. (1985). Military Civic Action in Colombia (Tesis de Maestría). University of Florida.

El ejército y el campesino. (1963, agosto). Periódico del Ejército.

El Plan Lazo. (1964, marzo). Periódico del Ejército, p. 17. 
Emboscadas, campos minados y pena de muerte encuentra el Ejército. (1964, junio 4). El Tiempo.

Estamos en la resistencia contra la opresión, dicen campesinas de Marquetalia. (1964, agosto 20). Voz proletaria.

Ferro, J. G., Medina, J. G. F., \& Uribe, G. (2002). El orden de la guerra: Las FARC-EP, entre la organización y la política. Pontificia Universidad Javeriana.

Gestal, J. J. (2005). La viruela como arma biológica. En Agresivos químicos y microbiológicos en la guerra y en el terrorismo. Madrid: Real Academia Nacional de Farmacia.

HANnING, H. (1966). The peaceful uses of military forces. Survival, 8(1), 28-32. Recuperado de: https://doi.org/10.1080/00396336608440596

Henderson, J. D. (2006). La modernización en Colombia: Los años de Laureano Gómez, 1889-1965. Universidad de Antioquia.

JERVIS, R. (1980). The Impact of the Korean War on the Cold War. Journal of Conflict Resolution, 24(4), 563-592. Recuperado de: https://doi. org/10.1177/002200278002400401

Kroener, S. (2017). Das castristische Jahrzehnt (1959-1967). Kolumbien «im Schatten des Kubaners». Mesa Redonda / Neue Folge, 34.

La realidad de 1963. (1963, octubre). Periódico del Ejército.

LAPHAM, R., \& NoRling, B. (1996). Lapham's Raiders: Guerrillas in the Philippines, 1942-1945 (1st Edition edition). Lexington: University Press of Kentucky.

Las Fuerzas Militares se han hecho presentes en los Programas de Reforma Agraria. (1963, septiembre). Periódico del Ejército.

LeAL, F. (1994). El Oficio de la Guerra: La Seguridad Nacional en Colombia. Tercer Mundo Editores.

LEAL, F. (2002). La seguridad nacional a la deriva: Del Frente Nacional a la posguerra fría (1. ed). Bogotá, Colombia]: [Quito, Ecuador? Universidad de los Andes, CESO: Alfaomega; FLACSO, Sede Académico de Ecuador. 
MackenzIE, E. (2007). Las FARC: El fracaso de un terrorismo (1. ed). Bogotá: Debate.

Marquetalia 35 años después. (1999, junio 28). Semana.

Marquetalia, epicentro del plan. (1964, abril 15). El Espectador.

Marquetalia se confundirá con Colombia, si el apoyo a su lucha se acrecienta. (1964, julio 30). Voz proletaria.

Marulanda, A. (2003). La cuestión agraria y su incidencia en los orígenes de las Farc-ep (Documento No. 58. Centro de Estudios Socioculturales e Internacionales CESO.). Bogotá.

MELÉNDEZ, J. D. (2015). Colombia y su participación en la Guerra de Corea: Una reflexión tras 64 años de iniciado el conflicto. Historia y memoria, (10), 199-239. Recuperado de: https://doi.org/10.19053/20275137.3205

Molano, A. (2017). A lomo de mula. Viajes al corazón de las Farc (Aguilar). Bogotá: Aguilar.

Moreno Mancera, J. D. (2014). Relaciones cívico-militares en Colombia: Supremacía y control de los partidos políticos sobre la organización militar. Revista Científica General José María Córdova, 12(13), 333. Recuperado de: https://doi.org/10.21830/19006586.166

Nieto, P. A. N. (2014). El reformismo doctrinario en el Ejército colombiano: Una nueva aproximación para enfrentar la violencia, 1960-1965. Historia Crítica, (53), 155-176.

No destruirán a Marquetalia. (1964, agosto 27). Voz Proletaria.

No hay invasión militar. (1964, mayo 22). El Tiempo.

Nuevo método operacional. (1963, agosto). Periódico del Ejército.

Offstein, N., \& AristizÁbal, C. (2017). An Historical Review and Analysis of Colombian Guerrilla Movements: FARC, ELN and EPL1. Revista Desarrollo y Sociedad. Recuperado de: https://doi. org/10.13043/dys.52.4

Olave, G. (2013). El eterno retorno de Marquetalia: Sobre el mito fundacional de las FARC-EP. Folios, (37). Recuperado de: https:// doi.org/10.17227/01234870.37folios149.166 
Ortega, P. A. (2006). Historia de la Fuerza Aérea Colombiana. Recuperado 17 de septiembre de 2019, de El portal de la Aviación. Recuperado de: https://www.aviacol.net/historia-militar/historia-dela-fuerza-aerea-colombiana-fac.html

Pataquiva, N. (2009). Las Farc, su origen, su evolución. UNISCI Discussion Papers, (19).

PÉCAUT, D. (2008). Las FARC: ¿una guerrilla sin fin o sin fines? Bogotá: Norma.

Penagos, J. (2013). El proceso de representaciones sobre las FARC. 1964. Los inicios. Anagramas Rumbos y Sentidos de la Comunicación, 11(22). Recuperado de:: https://doi.org/10.22395/angr.v11n22a8

PizArRo, E. (1991). Las FARC (1949-1966): De la autodefensa a la combinación de todas las formas de lucha. UN, Instituto de Estudios Políticos y Relaciones Internacionales.

Pizarro Leongómez, E. P. (1987). La profesionalización militar en Colombia (II): El período de la violencia. Análisis Político, 0(2), 7-29.

PrÉSIGA Romero, S. (2018). Guerra psicológica: El poder de baja intensidad que transformó las Fuerzas Militares colombianas durante el periodo del Frente Nacional. 2(4), 15-23.

RAMSEY, R. W. (1981). Guerrilleros y soldados. Bogotá: Ediciones Tercer Mundo.

REMPE, D. M. (1995). Guerrillas, bandits, and independent republics: US counter-insurgency efforts in Colombia 1959-1965. Small Wars \& Insurgencies, 6(3), 304-327. Recuperado de:: https://doi. org/10.1080/09592319508423115

República de Colombia. (1962). Decreto 940 de 1962. Recuperado 17 de octubre de 2019. Recuperado de: http://www.suin-juriscol.gov.co/ viewDocument.asp?id=1193874

República de Colombia. (1963). Decreto 1381 De 1963. Recuperado 10 de octubre de 2019. Recuperado de:: http://www.suin-juriscol. gov.co/clp/contenidos.dl1/Decretos/1276621?fn=document-frame. $\mathrm{htm} \$ \mathrm{f}=$ templates $\$ 3.0$ 
Rodrigues, B. A. (1975). Smallpox eradication in the Americas. Bulletin of the Pan American Health Organization (PAHO), 9(1), 1975. Recuperado de: http://iris.paho.org/xmlui/handle/123456789/27699

RojAs, D. E. (2017). Una geografía global del combate. Asia y América Latina en los orígenes de la Guerra Fría. Contemporánea, 8, 55-72.

Rojas, D. M. (2010). La alianza para el progreso de Colombia. Análisis Político, 23(70), 91-124.

Rojas Delgado, J. E., Piraquive, H. E., Arango Arango, D., Sequera Gómez, N., Guevara Ospina, J. I., \& Pantoja Reyes, Y. C. (2017). Fuerzas Militares de Colombia Ejército Nacional V División: El conflicto armado en las regiones [WorkingPaper]. Recuperado de: http:/dx.doi.org/10.12804/issne.2590-5260_10336.14150_dicsh

Rothermund, D. (2006). The Routledge companion to decolonization. London and New York: Routledge.

RuEDA, R. (2000). De la guardia de las fronteras a la contrainsurgencia: Elementos de la evolución política e institucional del ejército colombiano 1958-1965. Bogotá: Icfes.

Ruiz NovoA, A. (1956). Enseñanzas de la Campaña de Corea aplicables al Ejército de Colombia. Bogotá: Antares.

Ruiz NovoA, A. (1965). El gran desafío. Ediciones Tercer Mundo.

Santos Pico, M. J., Mejía Roa, R., \& Mesa Moncada, J. (2007). Historia militar del Ejercíto de Colombia. Bogotá: Centro de Estudios Históricos del Ejército.

SANTRICH, J. (Ed.). (s.f.). Manuel Marulanda Vélez, el héroe insurgente de la Colombia de Bolívar. Montañas de la América Nuestra: FARC-EP.

Smith, N., Kauffman, H., \& Windle, C. (1969). Effects of Military Civic Action on Attitudes: An Empirical Study in Colombia. Washington D.C.: Center for Research in Social Systems, American University.

StodDen, W. P., \& Weiss, A. (2017). Interests and Foreign Policy: The Cuban Revolution and US Response, 1959-1961. Foreign Policy Analysis, 13(1), 74-92. Recuperado de: https://doi.org/10.1111/fpa.12067 
Stueck, W. (1997). The Korean War: An International History. Princeton University Press.

Torres, C. (2000). Fuerzas armadas y seguridad nacional. Planeta Colombiana Editorial.

TREJOS, L. F. (2015). Un actor no estatal en el escenario internacional.: El caso de las FARC-EP. Universidad del Norte.

Trejos, L. F., \& González, G. (2013). El Partido Comunista Colombiano y la combinación de todas las formas de lucha. Entre la simpatía internacional y las tensiones locales, 1961- 1981. Revista Izquierdas, 17, 64-80.

UgarRIZA, J. E., \& PABÓN, N. (2017). Militares y Guerrillas: La memoria histórica del conflicto armado en Colombia desde los archivos militares, 1958-2016. Segunda edición. Editorial Universidad del Rosario.

United States Army. (1962). FM 100-5: Field service regulations, operations, 1962. : Obsolete Military Manuals. Recuperado de: http:// cgsc.contentdm.oclc.org/cdm/ref/collection/p4013coll9/id/34

United States Congress. (1960). Communist Threat in Latin America: Hearings Before the United States House Committee on Foreign Affairs, Subcommittee on Inter-American Affairs, Eighty-Sixth Congress, Second Session, on June 17, 20, 24, 1960. U.S. Government Printing Office.

URIBE, M. V. (2007). Salvo el poder todo es ilusión: Mitos de origen: Eelam, de los Tigres Tamiles de Sri Lanka, Marquetalia, de las Fuerzas Armadas Revolucionarias de Colombia, y la Irlanda unida, del Provisional Irish Republican Army. Pontificia Universidad Javeriana. Valencia Tovar, A. (1992). Testimonio de una época. Bogotá: Planeta. VALENCIA Tovar, Á. (1993). Historia de las fuerzas militares de Colombia tomo III. Ejército. Bogotá: Planeta.

Valencia Tovar, Á. (2009). Mis adversarios guerrilleros. Planeta.

Valeriano, N. D., \& Bohannan, C. T. R. (2006). Counter-guerrilla operations: The Philippine experience. Westport, Conn.: Praeger Security International. 
VÉLEZ, M. M. (s. f.). Cuadernos de campaña. Recuperado 1 de octubre de 2019. Recuperado de: http://www.rebelion.org/docs/68099.pdf

Vezzetti, H. (2009). Sobre la violencia revolucionaria memorias y olvidos

(1 ed.). Recuperado de: http://core.cambeiro.com.ar/0-104313-25.pdf

VillamizaR, D. (2017). Las guerrillas en Colombia: Una historia desde los orígenes hasta los confines. Penguin Random House Grupo Editorial Colombia.

Villegas Arango, J. (1974). El libro negro de la represión: Frente Nacional, 1958-1974. Bogotá: Comité de Solidaridad con los Presos Políticos.

Whitaker, A. P. (1960). Our Reaction to Communist Infiltration in Latin America. The Annals of the American Academy of Political and Social Science, 330, 103-115. Recuperado de: JSTOR.

World Health Organization. (1964a). Notifications received from 6 to 12 November 1964 (Vol. 39).

World Health Organization. (1964b). Weekly Epidemiological Record, 1964, vol. 39, 20 (Vol. 39).

World Health Organization. (1965a). Notifications received from 6 to 12 August 1965 (Vol. 40).

World Health Organization. (1965b). Weekly Epidemiological Record, 1965, vol. 40, 04 (Vol. 40).

World Health Organization. (1965c). Weekly Epidemiological Record, 1965, vol. 40, 33 (Vol. 40). 